\title{
Conversion of Isopropylbenzene over AlSBA-15 Nanostructured Materials
}

\author{
Francine Mota Ribeiro1, Anne Michelle Garrido Pedrosa ${ }^{2}$, Marcelo José Barros de Souza1* \\ ${ }^{1}$ Department of Chemical Engineering, Federal University of Sergipe, São Cristovão, Brazil \\ ${ }^{2}$ Department of Chemistry, Federal University of Sergipe, São Cristovão, Brazil \\ Email: marcelojbs@ufs.br
}

Received 20 May 2014; revised 18 June 2014; accepted 3 July 2014

Copyright (C) 2014 by authors and Scientific Research Publishing Inc.

This work is licensed under the Creative Commons Attribution International License (CC BY).

http://creativecommons.org/licenses/by/4.0/

(c) (i) Open Access

\begin{abstract}
In this paper we studied the application of a series of AISBA-15 catalysts with different $\mathrm{Si} / \mathrm{Al}$ ratios on the reaction of conversion of isopropylbenzene. The catalysts were synthesized via hydrothermal method and characterized by nitrogen adsorption at $77 \mathrm{~K}$ and Small Angle $\mathrm{X}$-ray Scattering (SAXS). Catalytic tests were accomplished in a continuous flow fixed bed microreactor. The obtained results showed catalytic activity for all AISBA-15 catalysts producing benzene and propene as main products.
\end{abstract}

Keywords

AlSBA-15, Si/Al Ratio, Isopropylbenzene

\section{Introduction}

Several technological changes have occurred in the petroleum refining industry with the aim of improving the performance of these processes, which highlights the development of catalysts that provide higher activity and selectivity in the conversion of oil derived products with high aggregate value. Mesoporous catalysts of AlSBA-15 type show a high degree of accessibility [1], so it has been studied in cracking applications. The catalytic cracking process occurs in the presence of a catalyst which promotes the breaking of a carbon chain from long to smaller molecules, and increases the selectivity to desired products.

AlSBA-15 is a mesoporous material derived from SBA-15 (Santa Barbara Amorphous). SBA-15 is a mesoporous silicate which was discovered in the 90s by Zhao and collaborators [1]. These materials have well-defined pore diameter which can be adjusted between 2 and $30 \mathrm{~nm}$, and have very high BET surface area (>500 $\mathrm{m}^{2} / \mathrm{g}$ ), mesopores with hexagonally arranged, large pore wall thicknesses that result in high thermal and hydro"Corresponding author. 
thermal stability, greater than MCM-41 materials [2] [3]. These characteristics have involved many research fields such as adsorption, catalysis, separation, nanoscience, solid templates for other materials, among others [4].

Catalytic tests in laboratory units are typically carried out using reagent model molecules. In this paper, the isopropylbenzene was selected as model molecule, also known as cumene. This compound, an aromatic hydrocarbon (C9h12) represents oil fractions. In the catalytic, cracking of cumene typically is expected to obtain an olefin (propylene) and an aromatic (benzene) but depending on the type of catalyst and on the reaction scheme, other side reactions can occur with the obtaining of other products, which may be verified experimentally.

\section{Experiment}

The AlSBA-15 was synthesized by hydrothermal method with different atomic ratios of Si/Al (25, 50 and 75), using as structural template the Pluronic P123, tetraethyl orthosilicate as silica source, pseudobohemite as aluminum source, hydrochloric acid and distilled water as solvents. These reagents were mixed in order to obtain a hydrogel reactive with the following molar composition: 1.0 TEOS: 0.017 P123: $\mathrm{x} \mathrm{Al}_{2} \mathrm{O}_{3}$ : $5.7 \mathrm{HCl}: 193 \mathrm{H}_{2} \mathrm{O}$. Where $\mathrm{x}$ is $0.007(\mathrm{AlSBA}-15, \mathrm{Si} / \mathrm{Al}=75), 0.01(\mathrm{AlSBA}-15, \mathrm{Si} / \mathrm{Al}=50)$ and $0.02(\mathrm{AlSBA}-15, \mathrm{Si} / \mathrm{Al}=25)$.

The reagents were mixed in order to obtain a hydrogel reactive. First, the template was dissolved on the solvents under stirring and heating at $35^{\circ} \mathrm{C}$. Then there was added the required amount of pseudobohemite (AlOOH) to obtain a Si/Al ratio desired. The silica source was added for last and the mixture was stirred and heated at $35^{\circ} \mathrm{C}$ for 24 hours to obtain a homogeneous gel. The resultant gel was transferred to an autoclave and conditioned on the oven for 48 hours at $100^{\circ} \mathrm{C}$. The resulting products were vacuum filtered and washed with water, after this procedure the material has been placed to dry at room temperature for 24 hours.

The SAXS of the samples were obtained at a scan angle $0^{\circ}-5^{\circ}$ in an equipment SAXS1 of scattering X-ray small angle of the LNLS-National Laboratory Light Cyclotron in Campinas/SP/Brazil. The experiments were conducted using $\mathrm{CuK} \alpha$ radiation. The survey of $\mathrm{N}_{2}$ adsorption-desorption isotherms of the samples calcined AlSBA-15 was performed in a Quantachrome equipment NOVA1200 by nitrogen adsorption at a temperature of $77 \mathrm{~K}$.

The catalytic test was carried out in a fixed bed continuous flow rector manufactured by Altamira Instruments (BENCHCAT $4000 \mathrm{HP}$ ). The tests were conducted using a mass of $200.0 \mathrm{mg}$ of catalyst. Before the start of the reaction the catalysts were activated in situ under heating in nitrogen flow of $50 \mathrm{~mL} / \mathrm{min}$ starting from ambient temperature to the temperature of reaction $\left(350^{\circ} \mathrm{C}\right.$ or $\left.400^{\circ} \mathrm{C}\right)$ under a rate heating of $5^{\circ} \mathrm{C} / \mathrm{min}$. After reaching the reaction temperature, the reactor was isolated by diverting the flow through the bypass and at that moment the syringe liquid pump was thrown which drove a syringe containing liquid isopropylbenzene by capillary flow lines of the unit. The liquid injected through the syringe (at $50 \mu \mathrm{L} / \mathrm{min}$ ) was continuously vaporized, and being transported by the flow lines in a continuous which were heated at temperature of $200^{\circ} \mathrm{C}$. This were mixing with the stream of inert gas (nitrogen) for 10 minutes until the lines could be entirely filled from the mixture, after which time being directed to the reactor in a down flow in a WHSV (Weight Hourly Space Velocity) of $3 \mathrm{~h}^{-1}$. During the catalytic reactions, the reactor effluent gases are injected at time intervals of approximately 3.5 minutes, through a sampling valve Valco 6 pathways in a gas chromatograph equipped with a 6890N Agilent HP-5 column $-5 \%$ Methyl Phenyl siloxane $30 \mathrm{~m}$. Analysis of the products was performed using a FID detector.

\section{Results and Discussion}

\subsection{Catalyst Characterization}

The SAXS analysis of the materials obtained showed the diffraction patterns with reflection peaks in the interval of low Bragg angle (less than 5). According to Zhao [1], three diffraction peaks are observed for SBA-15 materials which are related to the crystal planes, whose Miller indices are (100), (110) and (200). These diffraction lines are associated with a two-dimensional hexagonal symmetry P6mm typical of SBA-15 materials [2] [5]. Figure 1(a) show the SAXS patterns obtained for AlSBA-15 samples with different Si/Al ratios and in the calcined form.

For the AlSBA 15 with $\mathrm{Si} / \mathrm{Al}$ ratio of 25 and 50 were observed a set of diffraction peak in the region of $2 \theta$ of $0.5^{\circ}$ to $3^{\circ}$ which are related to(100) plane and two less intense peaks related to (110) and (200) planes, which indicating a highly ordered hexagonal material. The diffraction intensity of reflection (100) the samples mentioned above indicates that the unit cell dimensions are the same as in material SBA-15 [6]. The sample with 


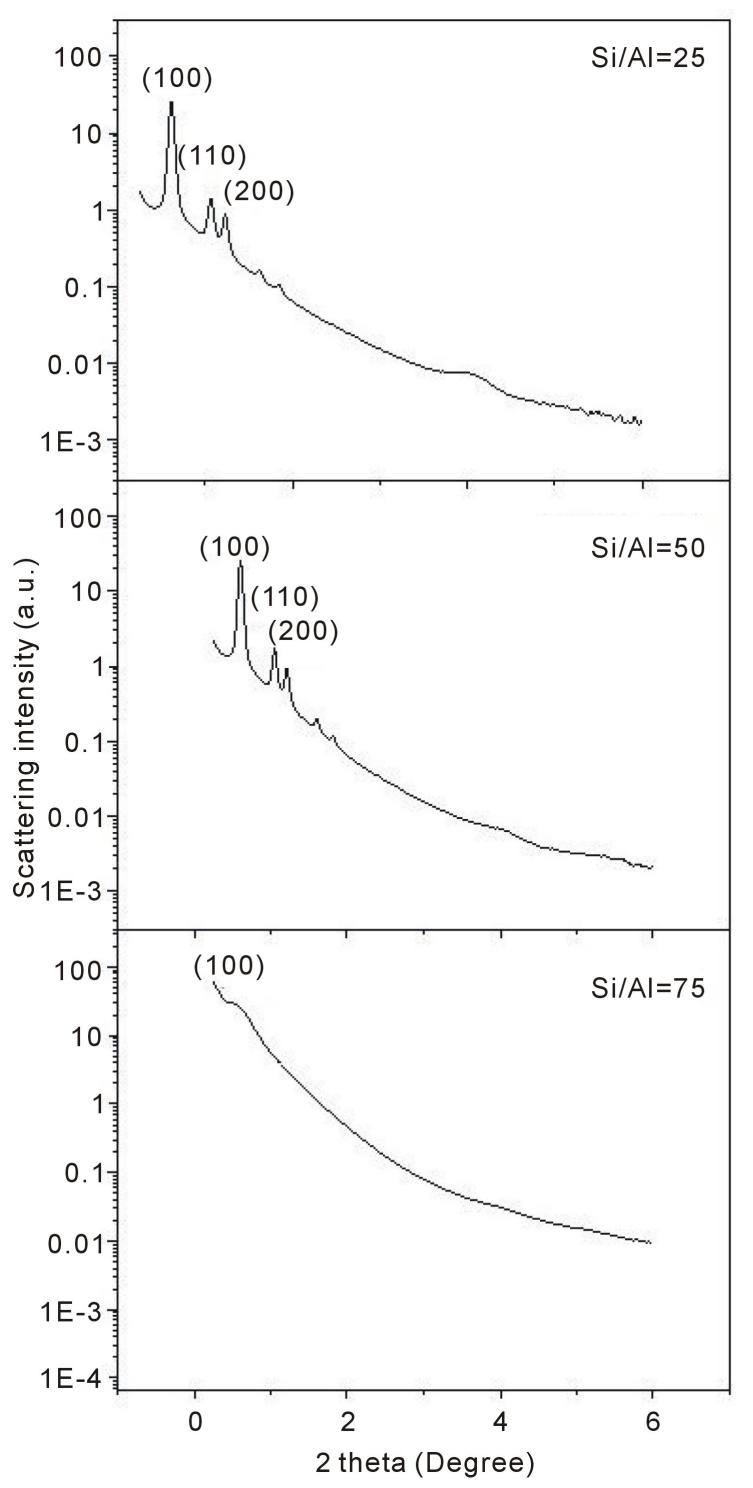

(a)

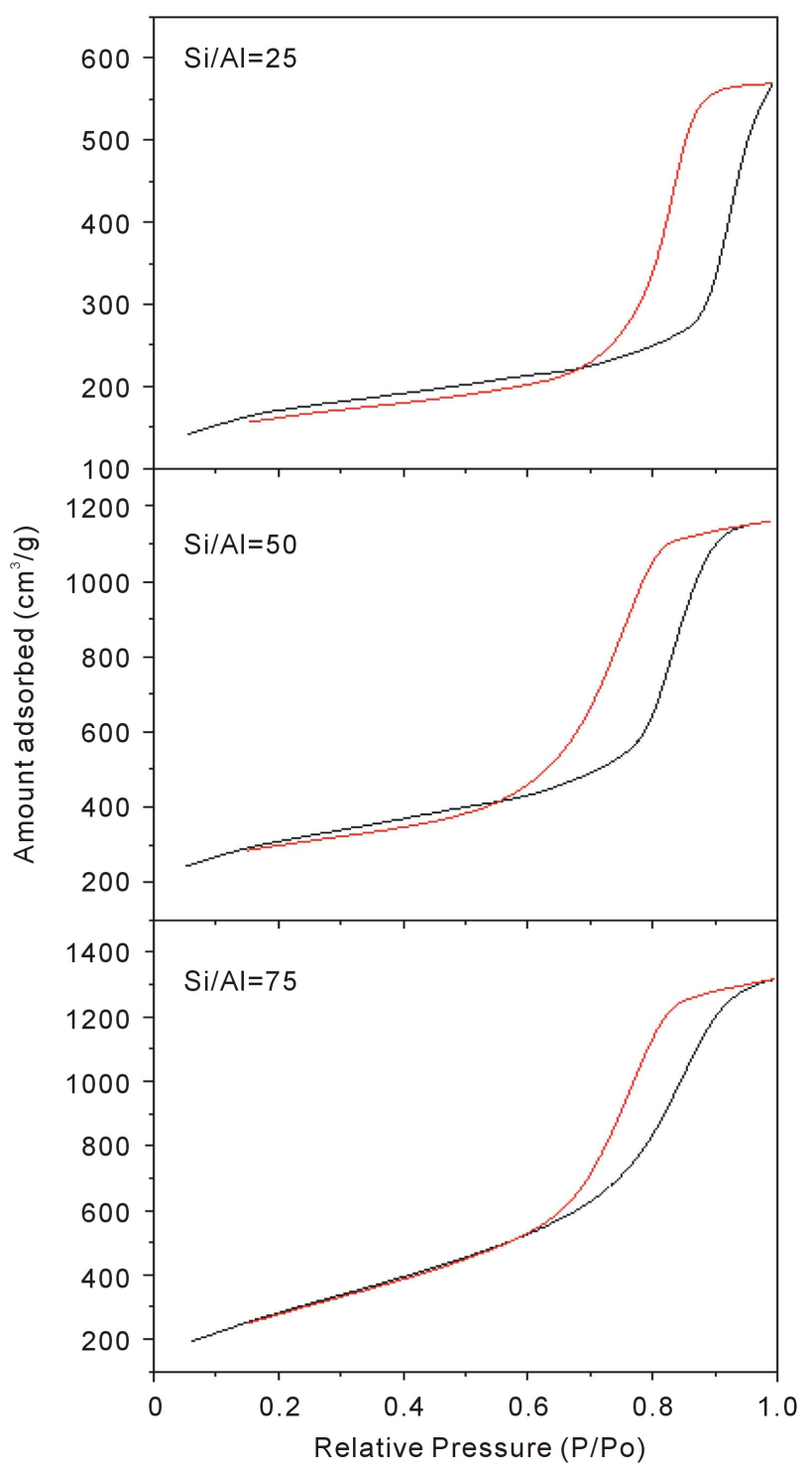

(b)

Figure 1. (a) SAXS analysis to the AlSBA-15 with different Si/Al ratios and (b) Adsorption-desorption isotherms of $\mathrm{N}_{2}$ to the AlSBA-15 with different $\mathrm{Si} / \mathrm{Al}$ ratios, where: black line = adsorption and red line = desorption.

$\mathrm{Si} / \mathrm{Al}$ ratio $=75$ no showed no characteristic peak to this material, this means that there was no formation of the structure.

The $\mathrm{N}_{2}$ adsorption-desorption isotherms obtained for the AlSBA-15 with Si/Al ratios of 25, 50 and 75 are shown in Figure 1(b). It can be observed that all samples exhibit adsorption/desorption isothermal of IV type in according to the IUPAC classification. The AlSBA-15 samples with $\mathrm{Si} / \mathrm{Al}=25$ and 50 showed a "loop" of hysteresis of type I, which is associated with the porous pellets consisting of hard spherical particles of uniform size ordered regularly [7]. Hysteresis of type I are typical of mesoporous materials, thus showing that the samples AlSBA-15 with ratios Si/Al $=25$ and 50 have mesoporous structure [4] [8]. The profiles of adsorption of each isotherm show a sharp increasing of the $N_{2}$ adsorbed in the range of relative pressure of 0.6 to 1.0. This suggests that the materials are very regular mesoporous channels with a narrow pore size distribution of gaussian [4] [8]. The position of the inflection points of P/Po is related to the pore size [4]. The hysteresis loop at a P/Po > 0.8 is corresponding to the inter particle capillary condensation in the pores and due to the presence of certain phases of impurities [8]. Table 1 shows the results of the textural characterization of the AlSBA-15 samples with ratios 
$\mathrm{Si} / \mathrm{Al}=25$ and 50.

\subsection{Catalytic Properties}

The catalytic conversion of isopropyl benzene was performed at two temperatures $\left(350^{\circ} \mathrm{C}\right.$ and $\left.400^{\circ} \mathrm{C}\right)$ in order to verify the effect of the temperature in the reactions. Figure 2(a) and Figure 2(b) shows the values of conversion as function of reaction time for different $\mathrm{Si} / \mathrm{Al}$ ratios at $350^{\circ} \mathrm{C}$ and $400^{\circ} \mathrm{C}$, respectively. At all reaction times it was observed that the conversion it was higher in temperature of $400^{\circ} \mathrm{C}$ than in the temperature of $350^{\circ} \mathrm{C}$ in the sample with $\mathrm{Si} / \mathrm{Al}=25$. At $400^{\circ} \mathrm{C}$ the conversion increased slightly as a function of reaction time and after 10 minutes the conversion stabilizes. This may be related to the deposition of coke on the surface of the material. At $350^{\circ} \mathrm{C}$ the conversion is maintained stabilized during the reaction time studied. Deactivation at high temperatures is common for this type of reaction where the continuous deposition of coke can inhibit the reaction. The influence of catalyst to oil ratio $(\mathrm{C} / \mathrm{O})$ in the conversion shows a similar behavior, where by analyzing the initial five minutes of reaction, it is observed that by increasing the catalyst mass, reach a maximum conversion of $\mathrm{C} / \mathrm{O}$ of 2.5 and 1.3 , at temperatures of $400^{\circ} \mathrm{C}$ to $350^{\circ} \mathrm{C}$, respectively. The same is observed with temperature, and as expected for this endothermic reaction that at low pressure, in the ideal gas state, increasing the temperature favors the conversion. The parameter $\mathrm{C} / \mathrm{O}$ becomes very important, because although it estimated at fixed bed conditions, is one of the commonly measured parameters during the catalytic cracking in fluidized bed reactors, where the load in a given $\mathrm{C} / \mathrm{O}$ ratio is cracked in the "riser" of FCC unit, giving the idea of the proportions of catalyst and oil used for the maximization of the conversion in each fluidized bed catalytic cycle.

For AlSBA-15 catalyst with $\mathrm{Si} / \mathrm{Al}=50$, conversion to $350^{\circ} \mathrm{C}$ remained relatively constant with flow time, indicating no apparent deactivation in the range examined. In this sample, the conversion at $400^{\circ} \mathrm{C}$ was low compared to the conversion at temperature of $350^{\circ} \mathrm{C}$. The drastic reduction of the conversion seen during the initial phase of the reaction indicated rapid coke formation, which occurs on the catalyst surface. Thus, in this reaction, the decrease in conversion to the long reaction time may be due to fast blockage of acid sites by the coke formed during the reaction. The same also occurred with respect to $\mathrm{C} / \mathrm{O}$ ratio, which show the conversion profile as a function of the $\mathrm{C} / \mathrm{O}$ ratio to the catalyst AlSBA-15 with $\mathrm{Si} / \mathrm{Al}=50$ with opposite behavior in comparison with AlSBA-15 with $\mathrm{Si} / \mathrm{Al}=25$. The temperature of $350^{\circ} \mathrm{C}$ showed higher conversion rates in function of $\mathrm{C} / \mathrm{O}$ ratio. But this data is consistent to that found in relation to the greater catalytic activity of the AlSBA-15 sample with $\mathrm{Si} / \mathrm{Al}=50$ at $350^{\circ} \mathrm{C}$. For this sample, in both cases (temperatures of $350^{\circ} \mathrm{C}$ to $400^{\circ} \mathrm{C}$ ), the best $\mathrm{C} / \mathrm{O}$ ratio was about 2. For the AlSBA-15 catalysts, through gas chromatography was observed the formation of benzene and propene as reaction products.

To the catalyst AlSBA-15 with Si/Al = 75 the conversion of ca. $1 \%$ to $5 \%$ were observed in the studied expe-

Table 1. Textural properties of the AlSBA-15 samples.

\begin{tabular}{ccccc}
\hline Samples & $\mathrm{SA}_{\mathrm{BET}}\left(\mathrm{m}^{2} \mathrm{~g}^{-1}\right)$ & $\mathrm{Vp}\left(\mathrm{cm}^{3} \mathrm{~g}^{-1}\right)$ & $\mathrm{Dp}$ BJH $(\mathrm{nm})$ & 12.5 \\
AlSBA-15 (25) & 555 & 0.9 & 4.3 & 8.8 \\
AlSBA-15 (50) & 1046 & 1.8 & 7.9 \\
\hline
\end{tabular}

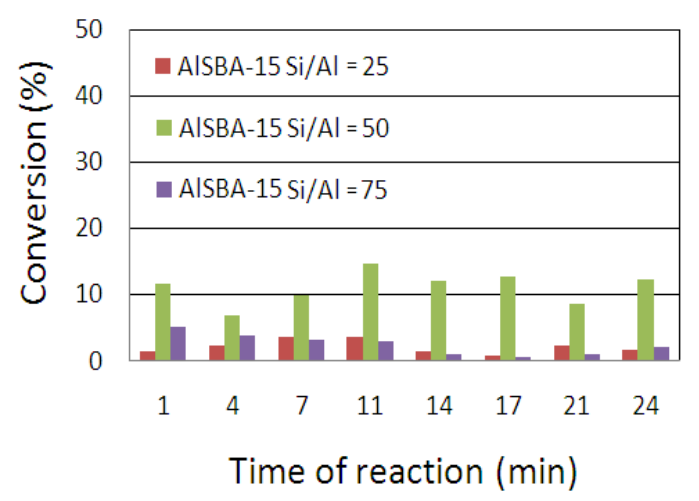

(a)

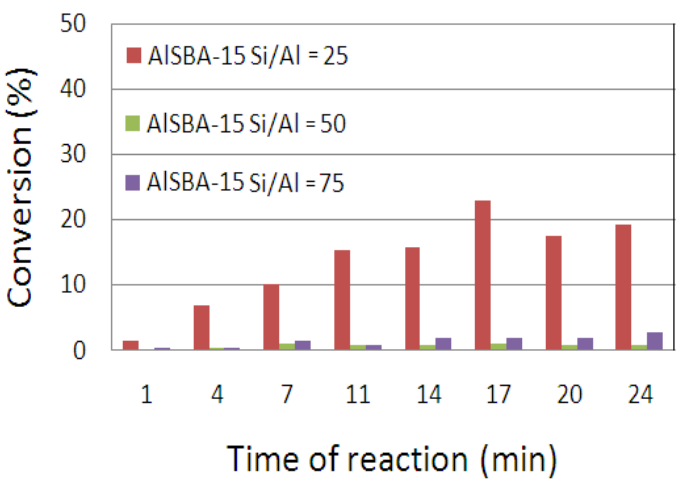

(b)

Figure 2. Conversion as function of reaction time for different $\mathrm{Si} / \mathrm{Al}$ ratios: (a) at $350^{\circ} \mathrm{C}$ and (b) at $400^{\circ} \mathrm{C}$. 
rimental conditions. This is attributed to the high $\mathrm{Si} / \mathrm{Al}$ ratio, thus making the material potentially less acidic to cracking. In this sample was not observed too the SBA-15 structure, as evidenced by SAXS analysis (Figure 1(a)). According Trejo [9], silica-alumina prepared by sol-gel method can produce a larger quantity of Brönsted acid sites most likely due to the homogeneity of $\mathrm{Al}$ atoms in the silica network by which is PEO the ability to generate more Brönsted acid sites on the surface of silica-alumina by forming hydrogen bonds with the silica during the sol-gel reactions. It has been reported that the oxygen atoms in the PEO can be coordinated with cations $\mathrm{Al}^{3+}$ and probably coordination affects the homogeneity on silica-alumina and the local structure of aluminum networks silica which promote the generation of a greater number of Brönsted acid sites. Thus, the method of preparation of the catalyst directly influences the amount of acidic sites present in the catalyst and its catalytic behavior consecutively.

\section{Conclusion}

AlSBA-15 catalysts were satisfactorily synthesized via hydrothermal method. The characterizations via nitrogen adsorption and SAXS evidenced that samples with Si/Al of 25 and 50 presented highly ordered structure with surface area in the range of 555 to $1046 \mathrm{~m}^{2} / \mathrm{g}$. Catalytic cracking of isopropyl benzene was studied on nanostructured materials such AlSBA-15 at different Si/Al ratios. During the reactions the formation of benzene and propene from direct cracking of isopropyl benzene model molecule was observed.

\section{Acknowledgements}

The authors acknowledge to Universidade Federal de Sergipe, with financial support from CENPES/ PETROBRAS (T.C. 4600286284 da Rede Temática de Desenvolvimento de Catálise), CAPES (Coordenação de Aperfeiçoamento de Pessoal de Nível Superior) and CNPq (Conselho Nacional de Desenvolvimento Científico e Tecnológico).

\section{References}

[1] Zhao, D., Feng, J., Huo, Q., Melosh, N., Fredrickson, G.H., Chmelka, B.F. and Stucky, G.D. (1998) Triblock Copolymer Syntheses of Mesoporous Silica with Periodic 50 to 300 Angstrom Pores. Science, 279, 548-552. http://dx.doi.org/10.1126/science.279.5350.548

[2] Katiyar, A., Yadav, S., Smirniotis, P. and Pinto, N.G. (2006) Synthesis of Ordered Large Pore SBA-15 Spherical Particles for Adsorption of Biomolecules. Journal of Chromatography A, 1122, 13-20. http://dx.doi.org/10.1016/j.chroma.2006.04.055

[3] Gédéon, A. Lassoued, A., Bonardet, J.L. and Fraissard, J. (2001) Surface Acidity Diagnosis and Catalytic Activity of AlSBA Materials Obtained by Direct Synthesis. Microporous and Mesoporous Materials, 44, 801-806. http://dx.doi.org/10.1016/s1387-1811(01)00263-3

[4] Wang, H. (1995) Magnetization and Interlayer Coupling in FeSi/Cu Compositionally Modulated Films. Physica Status Solidi (a), 147, 529-533. http://dx.doi.org/10.1002/pssa.2211470223

[5] Kumaran, G.M., Garg, S., Soni, K., Kumar, M., Gupta, J.K., Sharma, L.D., Rama Rao, K.S. and Murali Dhar, G. (2008) Synthesis and Characterization of Acidic Properties of Al-SBA-15 Materials with Varying Si/Al Ratios. Microporous and Mesoporous Materials, 114, 103-109. http://dx.doi.org/10.1016/j.micromeso.2007.12.021

[6] Han, Y.J., Kim, J.M. and Stucky, G.D. (2008) Preparation of Noble Metal Nanowires Using Hexagonal Mesoporous Silica SBA-15. Chemistry of Materials, 12, 2068-2069. http://dx.doi.org/10.1021/cm0010553

[7] Figueiredo, J.L. and Ribeiro, F.R. (1989) Catálise Heterogênea. 1st Edition, Fundação Calouste Gulbenkian, Lisboa.

[8] Li, Y., Yang, Q., Yang, J. and Li, C. (2006) Synthesis of Mesoporous Aluminosilicates with Low Si/Al Ratios Using a Single-Source Molecular Precursor under Acidic Conditions. Journal of Porous Materials, 13, 187-193. http://dx.doi.org/10.1007/s10934-006-8003-8

[9] Trejo, F., Rana, M.S. and Ancheyta, J. (2011) Genesis of Acid-Base Support Properties with Variations of Preparation Conditions: Cumene Cracking and Its Kinetics. Industrial \& Engineering Chemistry Research, 50, 2715-2725. http://dx.doi.org/10.1021/ie1008037. 
Scientific Research Publishing (SCIRP) is one of the largest Open Access journal publishers. It is currently publishing more than 200 open access, online, peer-reviewed journals covering a wide range of academic disciplines. SCIRP serves the worldwide academic communities and contributes to the progress and application of science with its publication.

Other selected journals from SCIRP are listed as below. Submit your manuscript to us via either submit@scirp.org or Online Submission Portal.
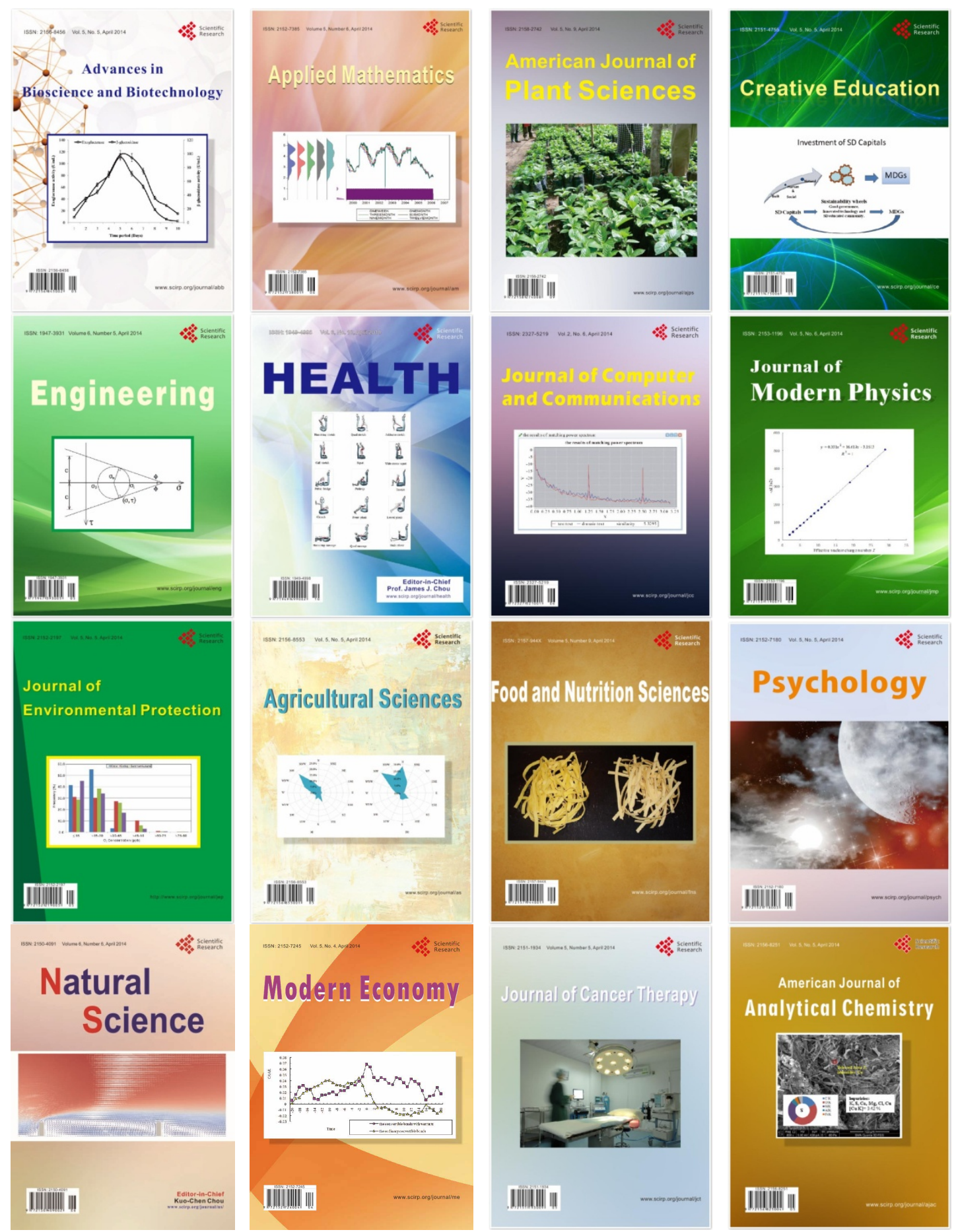